\title{
Comparison of foraging tool use in two species of myrmicine ants (Hymenoptera: Formicidae)
}

\author{
Gábor Módra ${ }^{1,3} \cdot$ István Maák ${ }^{1,2} \cdot$ Ádám Lőrincz ${ }^{1}$ Gábor Lőrinczi ${ }^{1}$ (1)
}

Received: 1 April 2021 / Revised: 14 August 2021 / Accepted: 18 October 2021 / Published online: 5 November 2021

(C) The Author(s) 2021

\begin{abstract}
Many ant species are known to exhibit foraging tool use, during which ants place various debris items (e.g., pieces of soil, leaves, pine needles, etc.) into liquid food, and then they carry the food-soaked tools back to the nest. In the present study, we compared the tool-using behavior in captive colonies of two closely related myrmicine ants with different feeding preferences: Aphaenogaster subterranea, an omnivorous species, and Messor structor, a mainly granivorous seed-harvester species. We supplied foraging ants with honey-water baits and six types of objects they could use as tools: sand grains, small soil grains, large soil grains, pine needles, leaves, and sponges. We found that the workers of A. subterranea both dropped more tools into honey-water baits and retrieved more of these tools than the workers of M. structor. While A. subterranea preferred smaller tools over larger ones, tool preferences for $M$. structor did not differ significantly from random. In addition, tool dropping was significantly faster in A. subterranea, and both the dropping and retrieving of tools began significantly earlier than in M. structor. For Aphaenogaster species that regularly utilize and compete for liquid food sources, the ability to efficiently transport liquid food via tools may be more important than it is for seed-harvester ants. Dropping tools into liquids, however, may still be useful for seed-harvester species as a means to supplement diet with liquid food during periods of seed shortage and also to serve as a means of getting rid of unwanted liquids close to the nest.
\end{abstract}

Keywords Aphaenogaster subterranea $\cdot$ Food transport $\cdot$ Feeding strategy $\cdot$ Messor structor $\cdot$ Tool-using behavior

\section{Introduction}

In the last few decades, the study of tool use has been a general interest among researchers of animal behavior. Even though there is an increasing number of publications in the topic, we know little about the origin of this behavior, especially in insects. One example of the many types of insect tool use is the foraging behavior of some myrmicine ants. During this behavior, ants place various debris items (e.g., pieces of soil, leaves, pine needles, etc.) into liquid food, and then they carry the food-soaked tools back to the nest (e.g., Fellers and Fellers 1976; Banschbach et al. 2006). The most

Gábor Lőrinczi

lorinczig@gmail.com

1 Department of Ecology, University of Szeged, Közép fasor 52, Szeged 6726, Hungary

2 Museum and Institute of Zoology, Polish Academy of Sciences, Wilcza Street 64, Warsaw 00-679, Poland

3 Doctoral School of Environmental Sciences, University of Szeged, Rerrich Béla tér 1, Szeged 6720, Hungary typical representatives of this behavior are the members of the genus Aphaenogaster (Fellers and Fellers 1976; Tanaka and Ono 1978; Fowler 1982; McDonald 1984; Agbogba 1985; Cerdá et al. 1988; Banschbach et al. 2006; Lórinczi 2014; Maák et al. 2017; Lórinczi et al. 2018; Maák et al. 2020; Módra et al. 2020), but it has also been observed in Messor barbarus (Durán 2011), Messor structor (Módra et al. 2017), Novomessor albisetosus (McDonald 1984; Wetterer et al. 2002), Pogonomyrmex badius (Morrill 1972), Solenopsis invicta (Barber et al. 1989; Qin et al. 2019), and Solenopsis richteri (Zhou et al. 2020). Contrary to the views of some authors (e.g., Durán 2011), this behavior completely satisfies the criteria of tool use (see Módra et al. 2020) according to the currently accepted definition, which is “... the exertion of control over a freely manipulable external object (the tool) with the goal of (1) altering the physical properties of another object, substance, surface or medium (the target, which may be the tool user or another organism) via a dynamic mechanical interaction, or (2) mediating the flow of information between the tool user and the 
environment or other organisms in the environment" (St. Amant and Horton 2008).

Although the tool-using behavior of Aphaenogaster species has been a subject of many studies in the past few years (Lórinczi 2014; Maák et al. 2017; Lórinczi et al. 2018; Maák et al. 2020; Módra et al. 2020), our knowledge of the foraging tool use of other myrmicine ants, as well as the origin of this behavior is rather limited. Furthermore, there is almost no direct evidence for the occurrence of foraging tool use in ants under natural conditions (i.e., in the wild on natural food sources). Based on a few observations and assumptions, rotten fruits, haemolymph of arthropods or droplets of honeydew released by hemipterans could trigger tool dropping in Aphaenogaster species (Fellers and Fellers 1976; Agbogba 1985; Módra et al. 2020). According to Alcock's (1972) hypothesis about the evolution of tool use, a nontool-using behavior could potentially evolve into tool use, given the appropriate ecological context and the suitable phenotypic change in the pre-existing behavior (Hunt et al. 2013). Many ant species cover liquids close to their nest to protect nestmate workers from drowning or entanglement (Wheeler 1910). This behavior may have evolved into foraging tool use (Fellers and Fellers 1976), and the fact that most of the known tool user species lack the ability to perform oral trophallaxis (Agbogba 1985) seems to support this hypothesis. Trophallaxis, i.e., the exchange of internally stored liquid food via regurgitation, is a common mechanism of sharing food among colony members in ants (Meurville and LeBoeuf 2021), and the absence of this fundamental ability may have fostered the development of alternative food-sharing methods in the affected groups of ants. Seedharvester ants belonging to the genus Messor, which are close relatives of Aphaenogaster species, are also known to use tools when feeding on liquids, at least in the laboratory or on artificial liquid baits (Durán 2011; Módra et al. 2017). Based on the observations of Durán (2011) with Messor barbarus, and the fact that Messor species are mainly granivorous (Plowes et al. 2013), we can postulate that they have different, presumably simpler tool-using behavior as compared to the mostly omnivorous members of the genus Aphaenogaster.

The aim of the present study was to compare the toolusing behavior of two closely related myrmicine ants with different feeding behaviors, A. subterranea, an omnivorous species, and $M$. structor, a granivorous species. We tested the hypothesis that due to the difference in diet, the toolusing behavior (i.e., the number of tools used, tool preference, and the rate of tool usage) differs in these two species, being more complex and vigorous in A. subterranea than in M. structor. Based on our hypothesis, we predicted that (1) more tools would be dropped and retrieved by the workers of A. subterranea than those of $M$. structor, (2) there would be a preference for the use of certain types of tools in
A. subterranea contrary to M. structor, (3) the rate of tool dropping would be faster in A. subterranea than in M. structor, and (4) the dropping and retrieving of tools would start earlier in A. subterranea as compared to M. structor.

\section{Methods}

\section{Study species}

Aphaenogaster subterranea (Latreille, 1798) (Fig. S1) is widely distributed in Europe and southwest Asia (Czechowski et al. 2012). Natural habitats are relatively humid and warm deciduous forests (Czechowski et al. 2012; Seifert 2018). Nests are usually built under stones, wood logs or at bases of trees, sometimes in decaying wood or in leaf litter (Lórinczi 2011; Czechowski et al. 2012; Seifert 2018). Colonies are thought to be monogynous with up to several thousand workers (Czechowski et al. 2012; Seifert 2018). Zoophagous and has trophobiotic relationships with various subterranean hemipterans (Lőrinczi 2012; Seifert 2018), but also feeds on seeds and elaiosomes (Bas et al. 2009).

Messor structor (Latreille, 1798) (Fig. S1) is widely distributed in Europe, west Asia, and central Asia (Czechowski et al. 2012). Natural habitats are xerothermous grasslands with rich seed vegetation. Nests are built in the soil with usually no other above-ground structure than weak rings of ejected soil material. Colonies are often polygynous and polydomous with up to several thousand workers (Seifert 2018). A granivorous and frugivorous species, but during periods of seed shortage diet is supplemented by other plant parts, arthropod carcasses, and fecal droppings of birds and mammals (Czechowski et al. 2012; Seifert 2018).

\section{Laboratory experiments}

We worked with five laboratory-reared colonies each of A. subterranea and M. structor. The colonies of both species originated from individual colony-founding queens, which were collected from different locations. Colonies were about the same size with approximately $25-40$ workers and a single queen. We housed the colonies in plastic boxes $(\mathrm{L}$ $12 \mathrm{~cm} \times \mathrm{W} 12 \mathrm{~cm} \times \mathrm{H} 10 \mathrm{~cm}$ ) with natural nesting materials (soil, leaf litter). Nest boxes were connected with a plastic tube ( $1 \mathrm{~cm}$ in diameter, $5 \mathrm{~cm}$ in length) to a foraging arena (L $13.5 \mathrm{~cm} \times \mathrm{W} 10 \mathrm{~cm} \times \mathrm{H} 7.5 \mathrm{~cm}$ ) where the experiments were performed (Fig. 1). Colonies were kept under constant conditions (temperature $24 \pm 4{ }^{\circ} \mathrm{C} ; 14: 10 \mathrm{~h}$ light:dark cycle). Water was sprayed into the nest boxes every day to maintain humidity and to satisfy the water need of ants. Food was available only every second day to avoid losing interest in 
Fig. 1 Illustration of the methods used in the study

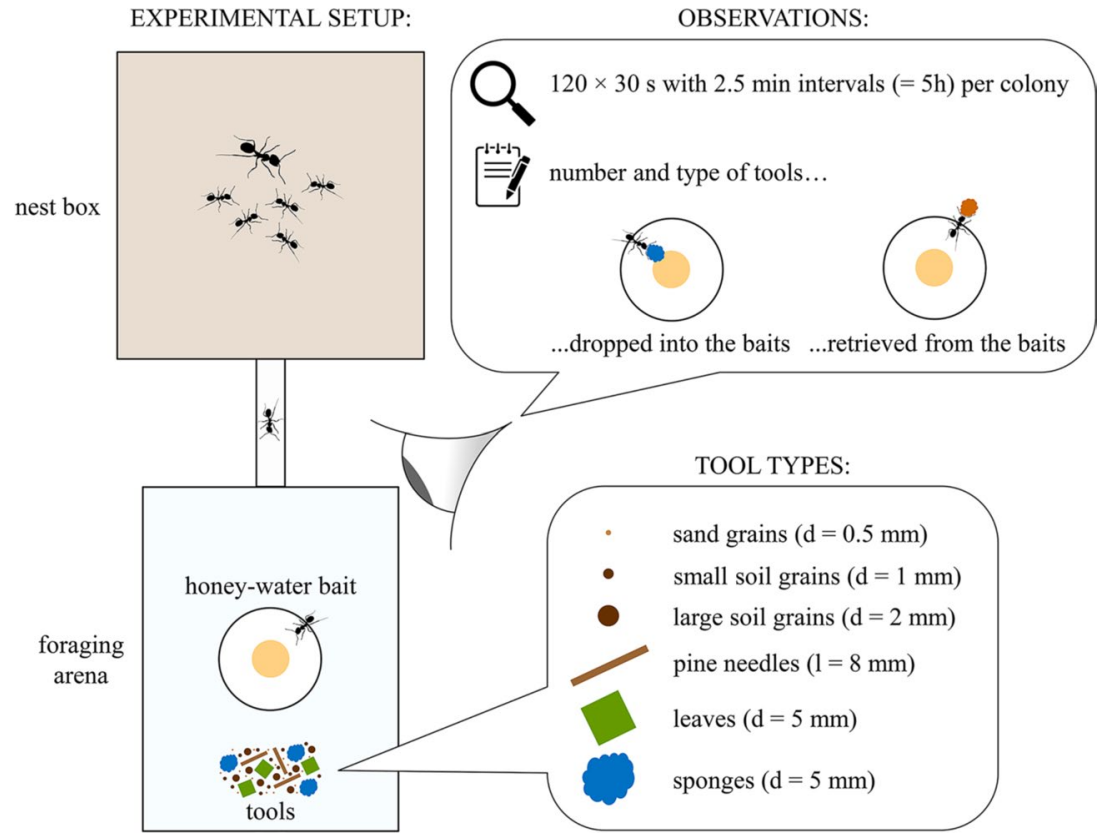

baits during the experiments. Experiments were preceded by four days of starvation period.

We used six types of objects as tools: sand grains (ca. $0.5 \mathrm{~mm}$ in diameter), small soil grains (ca. $1 \mathrm{~mm}$ in diameter), large soil grains (ca. $2 \mathrm{~mm}$ in diameter), pieces of pine needles (ca. $8 \mathrm{~mm}$ in length), pieces of leaves (ca. $5 \mathrm{~mm}$ in diameter), and pieces of sponges (ca. $5 \mathrm{~mm}$ in diameter) (Fig. 1). As baits, we used a mixture of honey and water (1:3), which was added as a single drop (ca. $0.5 \mathrm{ml}$ ) on a $4 \mathrm{~cm}$ diameter plastic disc (Fig. 1, Fig. S1). During the experiments, honey-water baits were placed in the centre of the foraging arena, $7 \mathrm{~cm}$ from the arena entrance (Fig. 1). Tools were mixed in equal volume, and a mixture (ca. $7 \mathrm{~cm}^{3}$ in total) was settled $4 \mathrm{~cm}$ from the baits. With this setup, we could avoid the effect of distance during tool selection (see Lőrinczi et al. 2018). Observation periods began when the first workers found the bait. Each observation period lasted $30 \mathrm{~s}$ and was repeated every two and half minutes for $5 \mathrm{~h}$ for each colony. During each observation period, we recorded the type and number of tools dropped into honey-water baits, and the type and number of food-soaked tools retrieved and transported to the nest. To minimize observer bias, blinded methods were used when all behavioral data were recorded.

\section{Data analysis}

Generalized linear mixed models (GLMM, Poisson error, maximum likelihood fit, $N=7200$ ) were used to test the effect of the ant species and the types of tools on the number of tools dropped into and retrieved from the baits. In the full models, the type of tools (sand grains, small and large soil grains, pine needles, leaves and sponges), the ant species and the interaction of the two were included as fixed factors, whereas the nest ID was a random factor.

The dropping rate of different tool types on the liquids was analyzed with a Cox regression model $(N=556)$. In the full model, the type of tools (sand grains, small and large soil grains, pine needles, leaves, and sponges), the ant species and the interaction of the two were included as fixed factors, whereas the nest ID was a random factor.

To compare the differences in timing between the two species we used randomization models $(N=10)$. We used different models to compare the time when the tool dropping into baits and when the tool retrieving from the baits started, whereas also the time spent between the two was considered. In every case, we built one model for all of the combinations $(N=252)$ of the values found for different colonies belonging to different species. The $p$ values were gained after summing up the results of all the models.

All statistical analyses were carried out in the R Statistical Environment (R Core Team 2019). If necessary, the variables were log-transformed prior to the analyses to meet the normality and homogeneity of variances. In model overdispersion, a negative binomial error structure was applied (see Lindén and Mäntyniemi 2011). GLMMs were performed using the glmer function in lme4 package (Bates et al. 2015), automated model selection with the help of dredge function in MuMIn package, whereas the coefficients of determination for linear mixed-effect models were calculated using the r.squaredGLMM function from the MuMIn package (Barton 2019). The fit of the mixed-effect linear models with a random term (nest ID) was compared with the corresponding GLMs (without nest ID as a random term) using the anova function. Cox regression analysis were performed with the 
help of coxme function in coxme package (Therneau 2019). Post hoc sequential comparisons (Tukey HSD) among factor levels when performing GLMM and Cox regression analysis were performed using emmeans function from emmeans package (Russell 2019). The number of all combinations in the randomization models were calculated using the $\operatorname{CombN}$ function, whereas the random combination of all the values were gained by the Combset function in DescTools package (Signorell et al. 2020). The values were picked up in a random manner with the vsetdiff function in vecsets package (Witthoft 2018).

\section{Results}

\section{Number of tools used}

We have found one A. subterranea colony that proportionally dropped (183) and retrieved (119) twice as many tools in total than the average ( mean $_{\text {dropping: }}: 93.8$ mean $\left._{\text {retrieving }}: 61.4\right)$, whereas one colony dropped (48) and retrieved (27) about half of the average number of tools (Figs. 2, 3). However, this latter (lowest) value was twice as high (dropping: 28, retrieving: 16) as the most elevated numbers found in Messor colonies (mean dropping $_{14}$; mean retrieving: $_{\text {) }}$ (Figs. 2, 3).

Overall, the workers of $A$. subterranea dropped significantly more tools into honey-water baits than those of $M$. structor (GLMM $z=9.33, p<0.001$ ). In $M$. structor, significantly fewer sand grains $(z=-9.33$, $p<0.001)$, small soil grains $(z=-8.45, p<0.001)$ and large soil grains $(z=-1.98, p=0.047)$ were dropped as compared to $A$. subterranea. In contrast, the workers

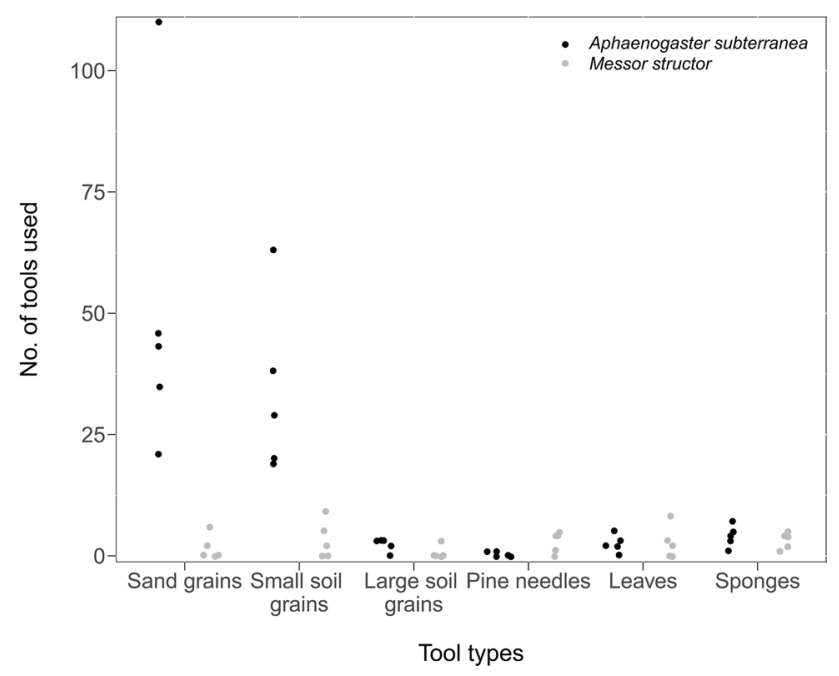

Fig. 2 The number of different types of tools dropped into honeywater baits by the workers of Aphaenogaster subterranea (black dots) and Messor structor (grey dots)

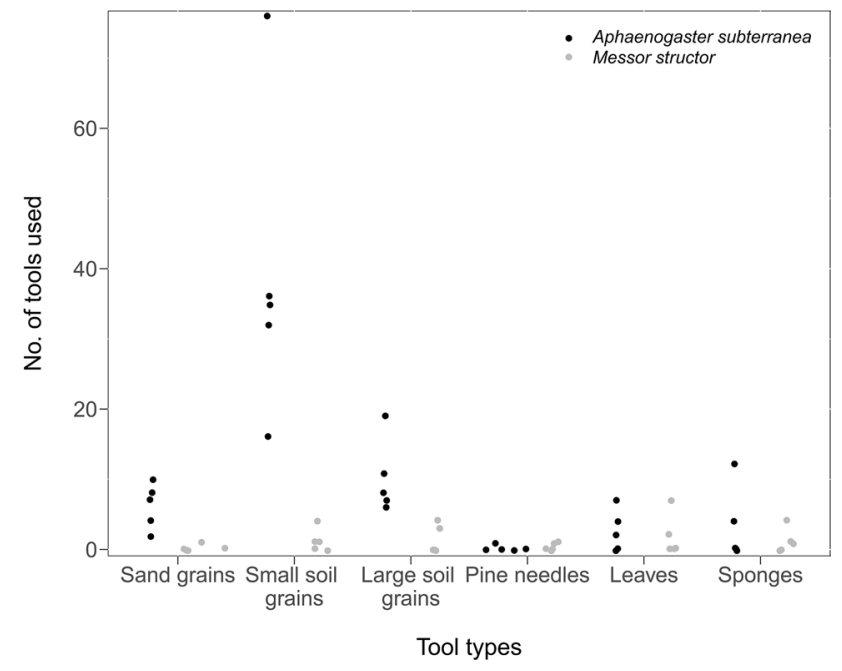

Fig. 3 The number of different types of tools retrieved from honeywater baits by the workers of Aphaenogaster subterranea (black dots) and Messor structor (grey dots)

of $M$. structor dropped significantly more pine needles $(z=2.58, p<0.01)$. In the case of leaves and sponges there were no significant differences between the two species $(0.21<z<0.64, p>0.526)$. The differences among colonies (nest ID) were responsible only for $4.052 \%$ of the variation, although when removed, the difference between the two models became significant (anova $\mathrm{Chi}^{2}=8.26$, $p=0.004$ ). The marginal (the variance explained by the fixed effects) and conditional (variance explained by the entire model-both fixed and random effects) coefficient of determination for the model showed only slight differences $\left(R_{\text {marg. }}^{2}=0.377, R_{\text {cond. }}^{2}=0.386\right)$.

Overall, significantly more food-soaked tools were retrieved from baits by the workers of $A$. subterranea than those of $M$. structor $(z=4.49, p<0.001)$. In A. subterra$n e a$, significantly more sand grains $(z=4.486, p<0.001)$, small soil grains $(z=8.433, p<0.001)$, large soil grains $(z=4.943, p<0.001)$ and sponges $(z=2.058 p=0.0396)$ were retrieved than in $M$. structor. In the case of pine needles and leaves there were no significant differences between the two species $(-0.57<z<0.85, p>0.395)$. The differences among colonies (nest ID) were responsible for $12.7 \%$ of the variation, and when removed, the difference between the two models became significant (anova $\mathrm{Chi}^{2}=37.33, p<0.001$ ). The marginal (the variance explained by the fixed effects) and conditional (variance explained by the entire model-both fixed and random effects) coefficient of determination for the model showed only slight differences $\left(R_{\text {marg. }}^{2}=0.872, R_{\text {cond. }}^{2}=0.877\right)$. 


\section{Tool preference}

In $A$. subterranea, sand grains were the most $(2.98<z<10.11,0.001<p<0.035)$ and small soil grains the second most frequently dropped tools $(6.21<z<8.45$, $p<0.001$ ) (Fig. 2). There were no significant differences among the rest of the tools $(-2.35<z<2.22$, $p>0.176)$. In $M$. structor, there was no significant difference in the number of different tools dropped into the baits $(2.65<z<2.65, p>0.086)$ (Fig. 2).

During the retrieving of food-soaked tools, small soil grains were the most frequently used tools by the workers of A. subterranea $(5.32<z<9.65, p<0.001)$ followed by the large soil grains and sand grains (Fig. 3). However, there was no significant difference between the two latter tools $(z=2.19, p=0.240)$. There were also no significant differences among the rest of the tools $(0.56<z<2.72, p>0.071)$. Contrary to A. subterranea, the workers of $M$. structor showed no preference for any tools $(-1.94<z<1.57$, $p>0.381$ ) (Fig. 3). Sand grains were, however, retrieved in a significantly lower amount than any other tools $(-4.15<z<-3.74, p<0.01)$.

\section{Rate of tool usage}

Based on the rate of tool dropping, the workers of $A$. subterranea were significantly faster than those of $M$. structor $(z=3.55, p<0.001)$. In A. subterranea, sand grains $(6.54<z<12.85, p<0.001)$ and small soil grains $(8.26<z<9.89, p<0.001)$ were dropped in a significantly faster rate than the rest of the tools (Fig. 4). In M. structor, there were no significant differences among the dropping rates of different tools $(-2.01<z<2.21, p>0.231)$ (Fig. 5).

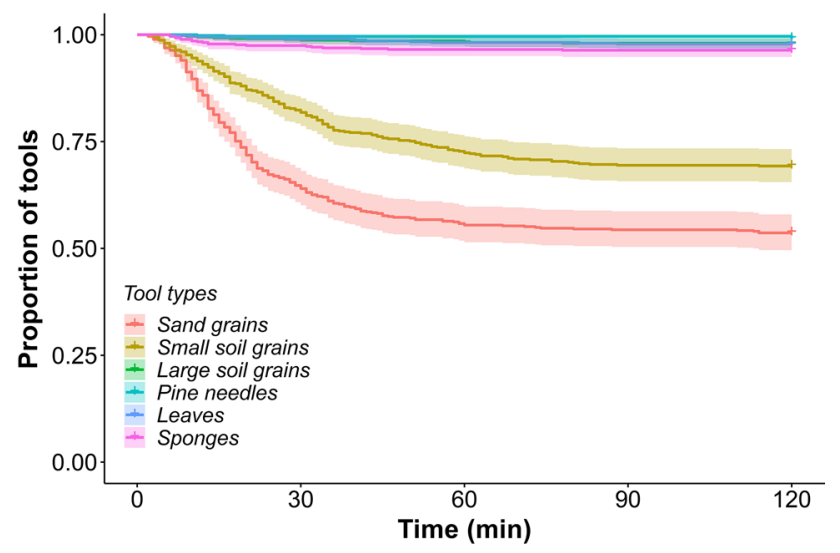

Fig. 4 The rate of tool dropping in Aphaenogaster subterranea represented as the changes in the proportion of undropped tools during the observation period. Different types of tools are depicted by different colors. The shaded areas represent $\pm 95 \%$ confidence intervals

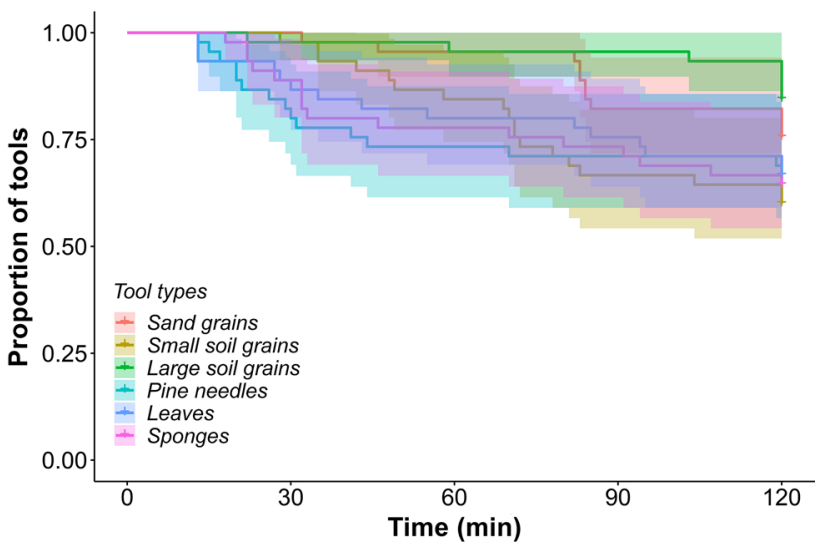

Fig. 5 The rate of tool dropping in Messor structor represented as the changes in the proportion of undropped tools during the observation period. Different types of tools are depicted by different colors. The shaded areas represent $\pm 95 \%$ confidence intervals

When comparing the time span between the discovery of baits and the beginning of tool dropping, and between the first dropping and retrieving event, the workers of $A$. subterranea began both the dropping and retrieving of tools significantly earlier than those of M. structor $(p<0.001)$.

\section{Discussion}

Although it has been known that the members of the genera Aphaenogaster and Messor can use tools to transport liquid food, no previous study has compared the tool-using behavior of these two taxa. Despite the variation present among the colonies of both species, our results support the hypothesis that the omnivorous $A$. subterranea shows many differences in the nature of its tool-using behavior when compared to $M$. structor, a mainly granivorous species. The foraging workers of $A$. subterranea dropped and retrieved significantly more tools into/from honey-water baits than those of $M$. structor, and the preference for the use of certain types of tools also differed in the two species: A. subterranea preferred smaller tools over larger ones, while M. structor showed no preference towards any specific tools. In addition, there was a strong difference in the rate of tool usage between the two species, as tool dropping was significantly faster in A. subterranea, and both the dropping and retrieving of tools began significantly earlier than in M. structor.

In our study, the workers of A. subterranea not just dropped and retrieved significantly more tools into/from honey-water baits, but also showed a faster rate of tool usage than the workers of M. structor. This may provide a selective advantage for these ants in interspecific competition because, by using tools, they can utilize food sources before a dominant competitor can monopolize them. Even 
when displaced from food sources, Aphaenogaster workers can return at a later time and retrieve the food-soaked tools which are usually ignored by other species (Fellers and Fellers 1976). Moreover, it was shown that other ants are less likely to discover food sources that were previously covered with tools (Fowler 1982; Banschbach et al. 2006; Lőrinczi 2014). Beyond giving an edge in competition, this food hiding behavior can also allow satiated colonies to store food for later consumption (Banschbach et al. 2006; Qin et al. 2019). Although the workers of M. structor also retrieved some food-soaked tools to the nests, this process was not as fluent and effective as was observed in the similar-sized A. subterranea colonies. By the end of the 5-h experiment, the provided food source was fully utilized by the workers of A. subterranea, while in M. structor the majority of the food was left behind. It seems that for seed-harvester ants like M. structor or M. barbarus it is not crucial to obtain liquids as fast as possible contrary to omnivorous species that utilize liquid food sources (e.g., honeydew) on a regular basis. Despite this, tool use may still have some adaptive value in seed-harvester ants, especially when, for example, local seed sources are not available but there are other opportunities to acquire food for the colony.

The tool-dropping workers of A. subterranea preferred sand grains and small soil grains over larger tools, and they dropped these tools into honey-water baits significantly faster than the rest of the tools. This result is consistent with other publications showing that the workers of A. subterranea use the most easily manageable tools during foraging, supposedly to maximize the speed of the tool-using process (Maák et al. 2017; Lőrinczi et al. 2018; Módra et al. 2020). The sizes of the most frequently used sand grains (ca. $0.5 \mathrm{~mm}$ in diameter) and small soil grains (ca. $1 \mathrm{~mm}$ in diameter) are well in the range of the maximum mandible gap of A. subterranea workers (0.8-1.2 $\mathrm{mm}$ ) (Oliveras et al. 2005), allowing them to manipulate these tools easier and faster than the larger ones. Contrary to the preference shown towards sand grains during tool dropping, soil grains turned out to be the most frequently used tools when it came to retrieving. This result is consistent with recent studies showing that the workers of $A$. subterranea can optimize their tool use at two stages, first, when dropping tools, and second, when retrieving food-soaked tools based on several factors, such as the viscosity of the liquid food (Lórinczi et al. 2018). Contrary to A. subterranea, the workers of M. structor showed no preference towards any specific tools neither during dropping, nor during retrieving. Probably because of the aforementioned reasons, effectiveness in tool dropping is not as significant for seed-harvester ants as for Aphaenogaster species.

In conclusion, the omnivorous $A$. subterranea has more flexible and effective tool-using skills when foraging on liquid food than the granivorous $M$. structor, whose toolusing behavior appears to be less complex and vigorous. Considering the high number of tool user species in the basal myrmicine lineages, i.e., in the tribes Stenammini and Pogonomyrmecini, we can assume that there was a common tool user ancestor in the basal part of the subfamily. The ability to use tools for foraging in Messor species thus seems to be a plesiomorphic character, which, after the Middle Miocene ( 16 mya) divergence of the genera Aphaenogaster and Messor (Ward et al. 2015), did not disappear entirely in taxa specialized in feeding on seeds. A remnant behavior like this is not unique among animals, for instance, although some whiptail lizards in the Aspidoscelis genus reproduce by parthenogenesis, two females sometimes perform fake copulation which can be considered as the legacy of their bisexually reproducing ancestors (Cole 1975). For seed-harvester ants, the ability to transport liquid food via tools may have lost its significance, but the possible benefits might have allowed the behavior to be preserved on a certain level. Dropping tools into liquids may still be adaptive for these species as a means to utilize liquid food sources if needed and also to serve as a means of getting rid of unwanted liquids close to the nest. The presence of such a behavioral remnant further demonstrates the diversity of the characteristics of foraging tool use in myrmicine ants, which poses several intriguing questions that are yet to be answered. For instance, it is still an open question whether the flexibility and effectiveness of the tool-using behavior of Aphaenogaster species can be considered widespread in the omnivorous tool user ant species or it is a unique characteristic of the members of this genus. More detailed surveys of the nature of this behavior in members of other myrmicine genera may help to answer this question, and the analysis of the distribution pattern of foraging tool use within the subfamily will help to provide deeper insights into the origin and evolution of tool-using behavior in ants.

Supplementary Information The online version contains supplementary material available at https://doi.org/10.1007/s00040-021-00838-0.

Author contributions GM, GL, and IM designed the experiment; GM, GL, IM, and ÁL carried out the experiments and data collection; IM carried out the data analysis. GM and GL wrote the manuscript, and all authors participated in the revision of the final version.

Funding Open access funding provided by University of Szeged. The authors did not receive support from any organization for the submitted work.

Data availability The data underlying all the results presented in the paper are available in Dryad Digital Repository: https://doi.org/10. 5061/dryad.0k6djhb0h. 
Code availability The $\mathrm{R}$ code used for the statistical analyses of this study is available from the second author on request.

\section{Declarations}

Conflict of interest The authors have no conflicts of interest to declare that are relevant to the content of this paper.

Ethics approval Colonies were maintained under nearly natural living conditions in the laboratory, thereby maximizing their welfare and survival. The experiments included only behavioral observations and non-invasive interactions with the ants. No individuals were intentionally harmed or disturbed. After the end of the experiments, colonies were kept in the laboratory until their natural death.

\section{Consent to participate Not applicable.}

Consent for publication All authors consent to publication of this paper. None of this work has been previously published nor is it submitted elsewhere.

Open Access This article is licensed under a Creative Commons Attribution 4.0 International License, which permits use, sharing, adaptation, distribution and reproduction in any medium or format, as long as you give appropriate credit to the original author(s) and the source, provide a link to the Creative Commons licence, and indicate if changes were made. The images or other third party material in this article are included in the article's Creative Commons licence, unless indicated otherwise in a credit line to the material. If material is not included in the article's Creative Commons licence and your intended use is not permitted by statutory regulation or exceeds the permitted use, you will need to obtain permission directly from the copyright holder. To view a copy of this licence, visit http://creativecommons.org/licenses/by/4.0/.

\section{References}

Agbogba C (1985) Observations on foraging of liquid sugar and insect body fluids by two species of Aphaenogaster: A. senilis and $A$. subterranea (Hym. Formicidae) (in French with English abstract). Insect Soc 32:427-434

Alcock J (1972) The evolution of the use of tools by feeding animals. Evolution 26:464-473. https://doi.org/10.1111/j.1558-5646.1972. tb01950.x

Banschbach VS, Brunelle A, Bartlett KM, Grivetti JY, Yeamans RL (2006) Tool use by the forest ant Aphaenogaster rudis: ecology and task allocation. Insec Soc 53:463-471. https://doi.org/10. 1007/s00040-006-0897-2

Barber JT, Ellgaard EG, Thien LB, Stack AE (1989) The use of tools for food transportation by the imported fire ant, Solenopsis invicta. Anim Behav 38:550-552. https://doi.org/10.1016/S0003-3472(89) 80052-1

Bartoń K (2019) MuMIn: multi-model inference. R package version 1.43.6. https://CRAN.R-project.org/package $=$ MuMIn

Bas JM, Oliveras J, Gómez C (2009) Myrmecochory and short-term seed fate in Rhamnus alaternus: Ant species and seed characteristics. Acta Oecol 35:380-384. https://doi.org/10.1016/j.actao. 2009.02.003

Bates D, Maechler M, Bolker B, Walker S (2015) Fitting linear mixedeffects models using lme4. J Stat Softw 67:1-48. https://doi.org/ $10.18637 /$ jss.v067.i01
Cerdá X, Bosch J, Alsina A, Retana J (1988) Dietary spectrum and activity patterns of Aphaenogaster senilis (Hymenoptera: Formicidae). Soc Entomol Fr 24:69-75

Cole CJ (1975) Evolution of parthenogenetic species of reptiles. In: Reinboth R (ed) Intersexuality in the animal kingdom. Springer, Berlin, pp 340-355

Czechowski W, Radchenko A, Czechowska W, Vepsäläinen K (2012) The ants (Hymenoptera, Formicidae) of Poland with reference to the myrmecofauna of Europe. MIZ PAS, Warszawa

Durán JMG (2011) Liquid food transport by means of solid items in Messor barbarus (Linnaeus, 1767), with a reconsideration of the so called "tool use behavior" in ants (in Spanish with English abstract). Iberomyrmex 3:9-20

Fellers JH, Fellers GM (1976) Tool use in a social insect and its implications for competitive interactions. Science 192:70-72. https:// doi.org/10.1126/science.192.4234.70

Fowler HG (1982) Tool use by Aphaenogaster ants: a reconsideration of its role in competitive interactions. B New Jersey Acad Sci 27:81-82

Hunt GR, Gray RD, Taylor AH (2013) Why is tool use rare in animals? In: Sanz CM, Call J, Boesch C (eds) Tool use in animals: cognition and ecology. Cambridge University Press, Cambridge, pp 89-118

Lindén A, Mäntyniemi S (2011) Using the negative binomial distribution to model overdispersion in ecological count data. Ecology 92:1414-1421. https://doi.org/10.1890/10-1831.1

Lőrinczi G (2011) Density and spatial pattern of nests in sub-Mediterranean ground-dwelling ant communities (Hymenoptera: Formicidae). Commun Ecol 12:51-57. https://doi.org/10.1556/ comec.12.2011.1.7

Lőrinczi G (2012) A novel association between Aphaenogaster subterranea (Hymenoptera: Formicidae) and the nymphs of Reptalus panzeri (Hemiptera: Cixiidae). Eur J Entomol 109:509-515. https://doi.org/10.14411/eje.2012.064

Lórinczi G (2014) Some notes on the tool-using behaviour of the ant, Aphaenogaster subterranea (Hymenoptera: Formicidae). Tiscia 40:17-24

Lőrinczi G, Módra G, Juhász O, Maák I (2018) Which tools to use? Choice optimization in the tool-using ant, Aphaenogaster subterranea. Behav Ecol 29:1444-1452. https://doi.org/10.1093/ beheco/ary 110

Maák I, Lőrinczi G, Quinquis PL, Módra G, Bovet D, Call J, d'Ettorre P (2017) Tool selection during foraging in two species of funnel ants. Anim Behav 123:207-216. https://doi.org/ 10.1016/j.anbehav.2016.11.005

Maák I, Roelandt G, d'Ettorre P (2020) A small number of workers with specific personality traits perform tool use in ants. Elife 9:e61298. https://doi.org/10.7554/eLife.61298

McDonald P (1984) Tool use by the ant, Novomessor albisetosus (Mayr). J N Y Entomol S 92:156-161

Meurville M-P, LeBoeuf AC (2021) Trophallaxis: the functions and evolution of social fluid exchange in ant colonies (Hymenoptera: Formicidae). Myrmecol News 31:1-30. https://doi.org/10. 25849/myrmecol.news_031:001

Módra G, Maák I, Lőrincz Á, Juhász O, Kiss PJ, Lőrinczi G (2020) Protective behavior or 'true' tool use? Scrutinizing the tool use behavior of ants. Ecol Evol 10:1-9. https://doi.org/10.1002/ ece 3.6968

Módra G, Lőrinczi G, Maák I (2017) Az eszközhasználat főbb jellegzetességei és adaptációs mechanizmusai a Myrmicinae hangyaalcsaládban. In: Koncz I, Szova I (eds) A 15 éves PEME XV. Ph.D. Konferenciájának előadásai, 1st edn. Professzorok az Európai Magyarországért Egyesület, Budapest, pp 67-74

Morrill WL (1972) Tool using behaviour of Pogonomyrmex badius (Hymenoptera: Formicidae). Fla Entomol 55:59-60 
Oliveras J, Bas JM, Gómez C (2005) Reduction of the ant mandible gap range after biotic homogenization caused by an ant invasion (Hymenoptera: Formicidae). Sociobiology 45:1-10

Plowes NJR, Johnson RA, Hölldobler B (2013) Foraging behavior in the ant genus Messor (Hymenoptera: Formicidae: Myrmicinae) Myrmecol News 18:33-49

Qin W, Chen X, Hooper-Bùi LM, Cai J, Wang L, Sun Z, Wen X, Wang C (2019) Food-burying behavior in red imported fire ants (Hymenoptera: Formicidae). J Life Environ Sci 7:e6349. https:// doi.org/10.7717/peerj.6349

R Core Team. (2019) R: a language and environment for statistical computing. Vienna (Austria). R Foundation for Statistical Computing. http://www.Rproject.org/

Russell VL (2019) Least-Squares Means: The R Package lsmeans. J Stat Softw 69:1-33. https://doi.org/10.18637/jss.v069.i01

Signorell A, Aho K, Alfons A, Anderegg N, Aragon T, Arppe A, Baddeley A, Bartoń K, Bolker B, Borchers HW (2020) DescTools: tools for descriptive statistics. $\mathrm{R}$ package version 0.99 .34

St. Amant R, Horton TE (2008) Revisiting the definition of animal tool use. Anim Behav 75:1199-1208. https://doi.org/10.1016/j. anbehav.2007.09.028
Tanaka T, Ono Y (1978) The tool use by foragers of Aphaenogaster famelica. Jpn J Ecol 28:49-58. https://doi.org/10.18960/seitai. 28.1_49

Therneau TM (2019) coxme: Mixed Effects Cox Models. R package version 2.2-14. https://CRAN.R-project.org/package $=$ coxme

Ward PS, Brady SG, Fisher BL, Schultz TR (2015) The evolution of myrmicine ants: phylogeny and biogeography of a hyperdiverse ant clade (Hymenoptera: Formicidae). Syst Entomol 40:61-81. https://doi.org/10.1111/syen.12090

Wetterer JK, Himler AG, Yospin MM (2002) Forager size, load size, and resource use in an omnivorous ant, Aphaenogaster albisetosa (Hymenoptera: Formicidae). Sociobiology 39:335-343

Wheeler WM (1910) Ants: Their structure, development, and behavior. Columbia University Press, New York, USA

Witthoft C (2018) vecsets: Like base: sets tools but keeps duplicate elements. R package version 1.2.1., https://CRAN.R-project.org/ package $=$ vecsets

Zhou A, Du Y, Chen J (2020) Ants adjust their tool use strategy in response to foraging risk. Funct Ecol 34:2524-2535. https://doi. org/10.1111/1365-2435.13671 